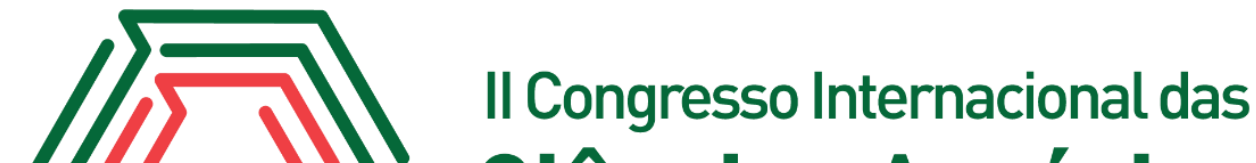 Ciências Agrárias COINTER - PDVAgro 2017
}

\section{DETERMINAÇÃO DA VELOCIDADE DE INFILTRAÇÃO PELO MÉTODO DO INFILTRÔMETRO DE ANEL NA ÁREA EXPERIMENTAL DO IFMA CAMPUS CODÓ - MA}

Apresentação: Pôster

Autor Principal ${ }^{1}$ Adriana Gomes dos Santos; Coautor $^{2}$ Ozely Ferreira dos Santos; Coautor ${ }^{3}$ Cristiane Rodrigues da Cruz; Orientador ${ }^{4}$ Wady Lima Castro Junior

\section{Introdução}

A água é um componente importante da natureza que desempenha função insubstituível no desenvolvimento dos seres vivos, desde os animais as plantas. Conhecer e saber como lidar com este elemento ocasionará ações eficientes nas mais variadas formas de uso, tanto na área animal no que diz respeito a quantidade necessária ao consumo, quanto na área das plantas na agricultura, por exemplo, para se usar na quantidade ideal e assim ser mais sustentável.

Entretanto, a agricultura, um dos setores de grande uso dos recursos hídricos, vem sendo assinalada como um dos setores principais de causas de manejo irracional da água. O que gera uma competição pela água cada vem mais acentuado e está ficando cada vez mais crítica na sua falta, uma vez que está trazendo degradação ambiental e provável falta futura para consumo e alimentação humana e animal, bem como a sua sobrevivência que depende intimamente da água (BRITO; ANDRADE, 2010).

Conhecer os métodos de determinação de velocidade de infiltração de água no solo (VI) é um dos meios para que a agricultura possa está diminuindo este desperdício e utilizando esta matéria prima supracitada de forma racional e como fator importante na irrigação, onde determinará, por exemplo, o tempo em que se deve manter a duração da aspersão nas culturas utilizadas nos sistemas de cultivo (BERNARDO et al., 2008 apud GONDIM et al., 2010).

\footnotetext{
${ }^{1}$ Curso Licenciatura em Ciências Agrárias, Instituição Instituto Federal de Educação, Ciência e tecnologia do maranhão, E-mail adrianagomes202@hotmail.com

${ }^{2}$ Curso Licenciatura em Ciências Agrárias, Instituição Instituto Federal de Educação, Ciência e Tecnologia do Maranhão, E-mail Ozely_santos@otmail.com

${ }^{3}$ Curso Licenciatura em Ciências Agrárias, Instituição Instituto federal de Educação, Ciência e Tecnologia do Maranhão, E-mail cryrodrigues18@hotmail.com

${ }^{4}$ Titulação Doutorado em irrigação e drenagem, Instituição Unb, E-mail wadycastro@ifma.edu.br
} 


\section{Fundamentação Teórica}

Segundo BERNARDO (1989), sob chuva ou irrigação contínua, a velocidade de infiltração se aproxima, gradualmente, de um valor mínimo e constante. Esse valor constante que a velocidade de infiltração atinge com o passar do tempo é conhecido por velocidade de infiltração básica (VIB). Assim sendo, sob chuva ou irrigação contínua, a taxa de infiltração se aproxima, gradualmente, de um valor mínimo e constante, conhecido por taxa de infiltração básica ou velocidade de infiltração básica (ALVES SOBRINHO et al., 2003). Ambos os autores afirmam como pode ser gradativamente a velocidade da água dependendo do seu tempo e infiltração no solo.

\section{Metodologia}

O trabalho foi desenvolvido em agosto de 2017, no campo experimental do Instituto Federal de Educação, Ciência e Tecnologia do Maranhão - IFMA, no munícipio de Codó, MA, com as coordenadas geográficas de $4^{\circ} 26^{\prime} 51^{\prime}$ ' S, $43^{\circ} 52^{\prime} 57^{\prime}$ ' O e com altitude de $48 \mathrm{~m}$ e classificado como uma área de solo Neossolo Quartzarênico (LOPES SOBRINHO et al., 2015).

A determinação da infiltração da água no solo foi realizada através do método do infiltrômetro de anel, ao qual constituiu por dois anéis, um externo e outro interno, abrangendo um menor com diâmetro de $25 \mathrm{~cm}$ (anel interno) e um maior com $50 \mathrm{~cm}$ (anel externo), ambos de altura de $30 \mathrm{~cm}$. "O anel externo tem como finalidade reduzir o efeito da dispersão lateral da água no anel interno, a qual deve ser infiltrada predominantemente na direção vertical" (SILVA et al., 2015, p. 986). Além dos anéis, foram utilizados dois baldes para carregamento de água, prancheta e papel para apoio da anotação das leituras, peça de madeira para aprofundamento dos anéis, régua para leitura e pregador para disposição da régua e um aparelho eletrônico para cronometragem do tempo de infiltração, como pode de ser observada uma parte destes materiais na figura 1 abaixo.

Figura 1 - Materiais utilizados e procedimento, Fonte: Autor, 2017.

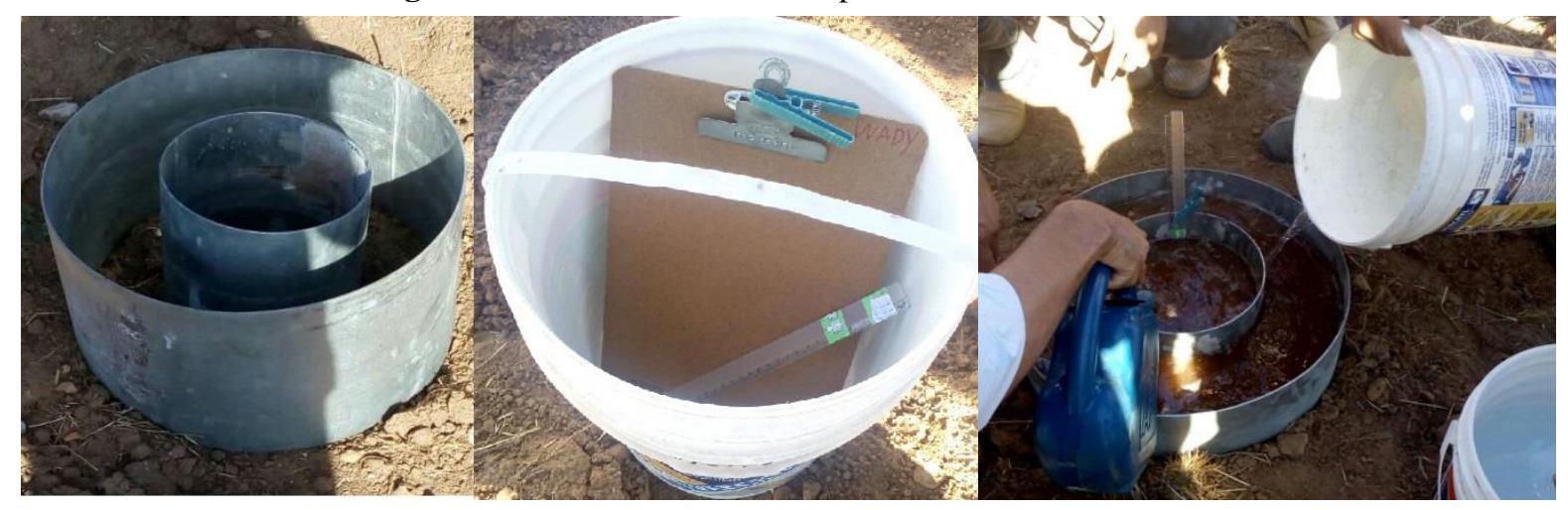


Os anéis foram posicionados e enterrados com aproximadamente $15 \mathrm{~cm}$ no solo, logo após isto foi feita a fixação da régua e pegaram-se os baldes com água e foi colocada água nos dois anéis simultaneamente até uma altura de $5 \mathrm{~cm}$ da régua e feita as anotações com uma coluna de tempo (min) e leitura $(\mathrm{cm})$ dos dados, como pode ser vista na Figura 1. Quando houve necessidade foram feitas a reposição de água. O teste permaneceu em percurso até o momento em que o valor da leitura do anel interno se repetiu por três vezes consecutivas.

A Velocidade de Infiltração Básica (VIB) foi determinada através da equação desenvolvida por Kostiakov, representada pelas equações potenciais abaixo representadas, segundo as utilizadas e resultados obtidos por Lopes Sobrinho et al. (2015) em seu trabalho:

$\mathrm{I}=\mathrm{aT}^{\mathrm{n}}$

em que esta primeira equação,

I= infiltração acumulada, em mm;

$\mathrm{T}=$ tempo de oportunidade de infiltração, em min;

a e $n=$ parâmetros de ajuste da equação.

Sendo aplicadas as operações logarítmicas correspondentes a esta primeira equação de infiltração. Logo, temos uma segunda equação: $\log I=\log a+n \log T$, que sua apresentação da equação de infiltração é uma equação reta do tipo $\mathrm{Y}=\mathrm{A}+\mathrm{BX}$ em que,

$\mathrm{Y}=\log$ I (infiltração acumulada);

$\mathrm{A}=\log \mathrm{a}$

$\mathrm{B}=\mathrm{n}$ (número de leituras realizadas com a régua);

$\mathrm{X}=\log \mathrm{T}$ (tempo acumulado)

$\mathrm{O}$ valor de $\mathrm{B}$ foi obtido com base na terceira equação abaixo:

$\frac{B=\sum X . Y-\frac{\sum X \cdot \sum Y}{N}}{\sum X^{2}-\frac{\left(\sum X\right)^{2}}{N}}$

\section{Resultados e Discussões}

O teste por meio do infiltrômetro de anel, com seus respectivos dados de valores de tempo e leitura, conforme tabela 1, foram capazes de serem calculados e assim encontrar os dados necessários para aplicação nas fórmulas.

Tabela 1 - Dados obtidos utilizando-se o teste com o infiltrômetro de anel, FONTE: Autor, 2017.

\begin{tabular}{|l|l|l|l|l|l|l|l|l|l|l|}
\hline Tempo & Tempo & Leitura & Diferença & Infiltração & VIm & VIa & $y=\operatorname{logI}$ & $\mathrm{x}=\log \mathrm{X}$ & $\mathrm{Xy}$ & $\mathrm{x}^{2}$ \\
\hline
\end{tabular}




\begin{tabular}{|c|c|c|c|c|c|c|c|c|c|c|}
\hline (min) & $\begin{array}{l}\text { Acumulado } \\
(\mathrm{min})\end{array}$ & $(\mathrm{cm})$ & $(\mathrm{mm})$ & $(\mathrm{mm})$ & $(\mathrm{mm} / \mathrm{h})$ & $(\mathrm{mm} / \mathrm{h})$ & & & & \\
\hline 0 & 0 & 5 & 0 & 0 & - & - & - & - & - & - \\
\hline $\begin{array}{c}55 \mathrm{~s}= \\
0,92 \mathrm{mi} \\
\mathrm{n}\end{array}$ & 0,92 & $3,4 / 5$ & 16 & 16 & 17,39 & 17,45 & 1,204 & $-0,036$ & $-0,043$ & $-1,296$ \\
\hline 5 & 5,92 & $4,2 / 5$ & 8 & 24 & 4,05 & 96,00 & 1,380 & 0,772 & 1,065 & 0,595 \\
\hline 5 & 10,92 & 4,5 & 5 & 29 & 2,65 & 60,00 & 1,462 & 1,038 & 1,517 & 1,077 \\
\hline 5 & 15,92 & $4 / 5$ & 5 & 34 & 2,13 & 60,00 & 1,531 & 1,201 & 1,838 & 1,442 \\
\hline 10 & 25,92 & 4,3 & 7 & 41 & 1,58 & 41,99 & 1,612 & 1,413 & 2,277 & 1,996 \\
\hline 10 & 32,92 & $3,5 / 5$ & 8 & 49 & 1,36 & 47,99 & 1,690 & 1,555 & 2,627 & 2,418 \\
\hline 15 & 50,92 & $4,1 / 5$ & 9 & 58 & 1,13 & $\mathbf{3 6}$ & 1,763 & 1,706 & 3,007 & 2,910 \\
\hline 15 & 65,92 & 4,1 & 9 & 67 & 1,01 & $\mathbf{3 6}$ & 1,826 & 1,819 & 3,321 & 3,308 \\
\hline 15 & 80,92 & 3,2 & 9 & 76 & 0,94 & $\mathbf{3 6}$ & 1,8808 & 1,908 & 3,588 & 3,640 \\
\hline
\end{tabular}

Na aplicação da terceira equação, obteve-se o resultado de B $=0,6201$. Na equação reta da segunda equação abrangendo as suas médias, o valor de A corresponde ao valor de 0,8101.

O valor de "a" é localizado através do emprego do antilog A, e "a" é o próprio valor de B: $\mathrm{a}=\operatorname{antilog} \mathrm{A}=10^{\mathrm{A}} \rightarrow 10^{0,8101} \rightarrow 6,458$

Com base nestas informações, podemos montar a equação de infiltração resultado destes dados: $\mathrm{I}=6,458 \mathrm{~T}^{0,6201}$.

A Velocidade de Infiltração Básica (VIB) correspondeu ao valor de $36 \mathrm{~mm} / \mathrm{h}$. Segundo Bernardo et al. (2006) citado por Silva et al. (2015) este valor nos remete uma classificação de VIB muito alta, no qual podemos caracterizar o solo com uma textura franco arenoso.

\section{Conclusões}

Tendo em vista a exposição dos resultados, podemos notar que na utilização da equação de Kostiakov, obteve-se uma $\mathrm{I}=6,458 \mathrm{~T}^{0,6201}$, com uma Velocidade de Infiltração Básica (VIB) de 36 $\mathrm{mm} /$ ha que é classificada como um solo de VIB muito alta. Este fato de ser explicada por uma gama de fatores, uma delas pode ser as características físicas do solo ao qual foi feito o teste.

\section{Referências}


BRITO, R. A. L.; ANDRADE, C. L. R. Qualidade da água na agricultura e no ambiente. Informe Agropecuário, Belo Horizonte, v. 31, n. 259, p. 50-57, nov./dez. 2010. Disponível em: https://ainfo.cnptia.embrapa.br/digital/bitstream/item/34978/1/Qualidade-agua.pdf. Acesso em: 05.09.2017.

CUNHA, J. L. X. L.; SIlVA, C. A.; COELHO, M. E. H.; FONTES, L. O.; SILVA, M. G. O.; SILVA, Í. N. Velocidade de infiltração da água em um latossoloamarelo submetido ao sistema de cultivo mínimo. Revista ACSA - Agropecuária Científica no Semi-Árido, v.7, n.01, pag. 30-35, janeiro/março, 2011.

GONDIM, T. M. S.; WANDERLEY, J. A. C.; SOUZA, J. M.; FILHO, J. C. F.; SOUSA, J. S. Infiltração e velocidade de infiltração de água pele método do infiltrômetro de anel em solo areno-argiloso. REBAGA (Pombal - PB - Brasil) v.4, n.1, p. 64-73, janeiro/dezembro, 2010. Disponível em: https://ainfo.cnptia.embrapa.br/digital/bitstream/item/27205/1/490-799-1-PB.pdf. Acesso em: 05.09.2017.

LOPES SOBRINHO, O. P.; CASTRO JÚNIOR, W. L.; D. A. S. C.; XAVIER, R. S.; SILVA, L. F. B.; BRITO, A. D. Determinação da velocidade de infiltração pelo método do infiltrômetro de anel em solo arenoso no município de Codó - MA. In: XXV CONIRD - Congresso Nacional de Irrigação e Drenagem, 2015, São Cristóvão, SE. Anais... Congresso Nacional de Irrigação e Drenagem. São Cristóvão, SE, 2015. p. 1479-1484.

SILVA, T. S.; BARRETO, J. A. S.; OLIVEIRA, F. A.; CIRILO, T. F.; CRUZ, R. M. L.; BARROS, A. C. Determinação da infiltração e velocidade de infiltração de água pelo método de infiltrômetro de anel em solo do agreste alagoano. In: XXV CONIRD - Congresso Nacional de Irrigação e Drenagem, 2015, São Cristóvão, SE. Anais... Congresso Nacional de Irrigação e Drenagem. São Cristóvão, SE, 2015. p. 984-989. 